\title{
On the Thermal Fatigue of a Room-Cured Neat Epoxy and Its Composite
}

\author{
Mbarka Mohamed1, Michel Johnson², Farid Taheri ${ }^{3 *}$ \\ ${ }^{1}$ Advanced Composites and Mechanics Research Laboratory, Dalhousie University, Halifax, Canada \\ ${ }^{2}$ Clean Technologies Research Institute, Dalhousie University, Halifax, Canada \\ ${ }^{3}$ Department of Mechanical Engineering, Dalhousie University, Halifax, Canada \\ Email: ^farid.taheri@dal.ca
}

How to cite this paper: Mohamed, M. Johnson, M. and Taheri, F. (2019) On the Thermal Fatigue of a Room-Cured Neat Epoxy and Its Composite. Open Journal of Composite Materials, 9, 145-163. https://doi.org/10.4236/ojcm.2019.92007

Received: February 22, 2019

Accepted: April 9, 2019

Published: April 12, 2019

Copyright (c) 2019 by author(s) and Scientific Research Publishing Inc. This work is licensed under the Creative Commons Attribution International License (CC BY 4.0). http://creativecommons.org/licenses/by/4.0/ Open Access

\begin{abstract}
An experimental investigation is conducted to evaluate the potential degradation in the mechanical properties of an epoxy resin and unidirectional glass fiber-reinforced epoxy (GFRE) as a result of exposure to fluctuating temperature. A commonly used room-cured epoxy resin and the GFRE are subjected to various numbers of thermal cycles (up to 1000 heating/cooling cycles). Mechanical tests are conducted to examine the influence of thermal cycles on the stiffness, ultimate strength and strain of the resin and its GFRE. The Fourier transform-Raman spectroscopy (FT-Raman) is conducted to investigate the influence of the thermal cycles on the resulting chemical changes and curing degree of the resin. In addition, the Differential Scanning Calorimetry (DSC) analysis is conducted to investigate the variation in the glass transition temperature $\left(\mathrm{T}_{\mathrm{g}}\right)$ of the resin as a function of the applied thermal cycles.
\end{abstract}

\section{Keywords}

Epoxy Resins, Composites, Mechanical Properties, Degradation,

Degree of Cure, Raman Spectroscopy

\section{Introduction}

Adhesives and fiber-reinforced composites often undergo thermal fluctuations; as a result, their mechanical properties (e.g. stiffness and strength) could be degraded. Thermal fluctuations often occur in real-life and depending on the configuration and purpose of a given structural system, the resulting degradation could adversely affect the performance of the system. An example of such a system would be adhesively bonded joints (ABJ). The performance of an $\mathrm{ABJ}$ mating fiber-reinforced polymer composites (FRP) can be significantly affected 
when subjected to thermal cycles, especially if the applied temperature is near or surpasses the glass transition temperature $\left(\mathrm{T}_{\mathrm{g}}\right)$ of the adhesive and resin forming its adherends. Degradation of polymers can also occur when they thermally fluctuate at freezing temperatures. Therefore, special care must be exercised when thermoset resins/adhesives and fiber-reinforced polymer composites (FRP) are used in structural applications that would be experiencing harsh environments [1]-[8].

Several researchers have investigated the influence of fuctuating temperatures on epoxy resins and FRP. For instance, Fiedler et al. [9] studied the influences of stress state and temperature (over a wide range of temperatures, i.e. $-50^{\circ} \mathrm{C}$ to $180^{\circ} \mathrm{C}$ ), on the yield strength and fracture response of five different epoxy resins, one of which was L135i, a room-temperature cured epoxy resin. The results of their mechanical tests conducted to evaluate the compressive, tensile, and shear strengths, and fractographic study of the fracture surfaces were correlated with the stress state-dependent strength of the resin.

It should be noted that the tensile strength of all bulk resins becomes affected by the in-service temperature, as well as the inherent glass transition temperature $\left(\mathrm{T}_{\mathrm{g}}\right)$ of resins. Moreover, brittle epoxy resins show an extended plastic deformation under a shear loading condition and elevated temperature before fracturing. Bascom and Cottington [10] investigated the effect of temperature on an elastomer-modified epoxy resin. They found that the bulk fracture toughness of the resin increased sharply when the test temperature neared $\mathrm{T}_{\mathrm{g}}$ of the resin, a similar phenomenon observed in the case of the unmodified resin. It was also observed that the adhesives' fracture energy broadened and shifted with increasing temperature at thicker bond lines.

In another study, Grohs [11] investigated and compared the constitutive properties of a two-part acrylic bulk adhesive experimentally. He assessed and compared both linear and nonlinear responses of the adhesive by conducting normal and shear tests. He concluded that the tests provided a straightforward and accurate means for predicting the in-situ performance of the adhesive in both linear and nonlinear regimes. It was also concluded that the conventional failure criteria could not predict the yield strength and plastic deformation of the in-situ adhesive. The reason for the shortfall was attributed to the fact that the conventional criteria are developed based on incorporating the properties of the materials in their bulk state, and they do not consider any stress singularities or loading eccentricities that could develop during testing. Moreover, the tensile testing of the bulk adhesive revealed non-uniform stress distribution within the adhesive. Moreover, the void existence caused nonuniform deformation of the bulk adhesive. Viana et al. [2] also studied the degradation of the mechanical response of epoxy adhesives as a function of temperature. Aged and unaged dogbone tensile specimens of two epoxy adhesives were tested under different environmental (temperature and moisture) conditions. The tensile properties of both adhesives were observed to be unaffected by the aging time. However, the tensile properties were affected by temperature and moisture. Moisture causes 
plasticization of resins, thereby reducing their strength, stiffness, and increasing their ductility. Da Silva and Adams [12] evaluated the mechanical properties of structural epoxy adhesives in tension and shear over a wide range of temperature (i.e. $-55^{\circ} \mathrm{C}$ to $200^{\circ} \mathrm{C}$ ). They examined three different adhesives; a bismaleimide adhesive formulated for use at high temperatures and two paste-form epoxies, for use at low temperatures. They concluded that the combination of bismaleimide and one of the paste adhesives (i.e. Supreme $10 \mathrm{HT}$ ), produced the most resilient joint with an excellent load carrying capacity in the selected temperature range.

In reference to investigations that evaluated the performance of fiber-reinforced composites under fluctuating temperatures, Hawileh et al. [13] evaluated degradation in the elastic modulus and tensile strength of E-glass fiber-reinforced plastic (FRP), carbon FRP, and their hybrids, under exposure to different temperature ranges (from $25^{\circ} \mathrm{C}$ to $300^{\circ} \mathrm{C}$ ) for $45 \mathrm{~min}$. The decrease in the mechanical properties of the E-glass FRP and carbon FRP sheets was more severe than that of the hybrid composite sheets. Reductions in the elastic modulus of E-glass FRP, carbon FRP, and their hybrids composites, when exposed to $250^{\circ} \mathrm{C}$ compared to those measured at room temperature, were approximately $28 \%, 26 \%$, and $9 \%$, respectively, while the tensile strength degradation levels were at $42 \%$, $31 \%$, and $35 \%$, respectively. Furthermore, the fibers of the specimens that were tested at low-temperature ranges (i.e. $100^{\circ} \mathrm{C}-150^{\circ} \mathrm{C}$ ) fractured in a brittle manner, while a splitting failure mode was observed in specimens that were tested at high-temperature ranges (i.e. $200^{\circ} \mathrm{C}-250^{\circ} \mathrm{C}$ ). In another notable study, Ou et al. [14] investigated the effect of strain rates and temperatures on mechanical properties of a unidirectional glass fiber-reinforced polymer. They presented the stress-strain response of the FRP at varying strain rates and elevated temperatures. The Weibull model was used to quantify the degree of variability in the tensile strengths, generating the parameters that could be used in future engineering applications of the FRP. Eslami et al. [15] also studied the effects of aging on the flexural stiffness and bending capacity of perforated glass fiber-reinforced epoxy composite tubes subjected to combined moisture and elevated temperatures $\left(60 \%\right.$ humidity and temperatures of $40^{\circ} \mathrm{C}, 60^{\circ} \mathrm{C}$ and $\left.80^{\circ} \mathrm{C}\right)$. Their results indicated that increase in temperature reduced the diffusion coefficient of the material, thus facilitating increased moisture absorption. As a result, the flexural stiffness and bending capacity of the FRP was degraded markedly. Kumar et al. [16] investigated the degradation of an IM7/997 carbon fiber-reinforced epoxy exposed to ultraviolet radiation and condensation. They concluded that the matrix-dominated properties were affected the most, with the transverse tensile strength decreasing by $29 \%$ after only 1000 hours of cyclic exposure to UV radiation and condensation. However, their FRP's longitudinal fiber-dominated properties were not affected by the exposure durations.

In another study, Grammatikos et al. [17] studied the effects of hygrothermal aging on the durability of a pultruded flat FRP sheet immersed in distilled water at $25^{\circ} \mathrm{C}, 40^{\circ} \mathrm{C}, 60^{\circ} \mathrm{C}$ and $80^{\circ} \mathrm{C}$ for 224 days. The tensile properties of their FRP remained practically unaffected by the aging, whereas matrix dominated shear 
properties experienced an initial decrease. Spectroscopy analysis showed no chemical degradation incidents on the fiber reinforcement surfaces, and infrared spectroscopy revealed superficial chemical alteration in the aged matrix. Furthermore, in another work, Grammatikos et al. [18] investigated the effects of thermal cycles on the structural integrity of a pultruded glass-FRP. The study investigated sets of dry and soaked FRP specimens conditioned in distilled water for 224 days, subjected to different temperatures, for a total of 300 cycles. Results showed significant degradation of the tensile and shear strengths of their soaked specimens, while a negligible degradation was observed in the dry samples' mechanical properties. Moreover, Dogan and Atas [19] experimentally investigated the effects of hygrothermal aging on the mechanical properties and impact behavior of unidirectional glass-epoxy composites. Their specimens were conditioned at a constant temperature of $95^{\circ} \mathrm{C}$ and a constant humidity of $70 \%$ for different periods of times, ranging from $0 \mathrm{~h}$ to $1200 \mathrm{~h}$. The properties evaluated were the modulus of elasticity, longitudinal, transverse and shear strengths, and Poisson's ratio. They concluded that the most influenced (or degraded) property was the transverse modulus of elasticity, while the least affected one was the shear modulus. Moreover, the perforation threshold of the composite materials also decreased by the increase of conditioning time.

In another study, Mahato et al. [20] studied the effect of the thermal spike on the response of glass/epoxy composite experimentally. Their specimens were exposed to $50^{\circ} \mathrm{C}, 100^{\circ} \mathrm{C}, 150^{\circ} \mathrm{C}$, and $200^{\circ} \mathrm{C}$ temperatures for a holding period of 5, 10, 15 and 20 minutes, respectively. The specimens were tested under tensile loading. Fractured surfaces were analyzed using a scanning electron microscope (SEM), and the glass transition temperature $\left(\mathrm{T}_{\mathrm{g}}\right)$ was evaluated. An increase in the ultimate tensile strength of the composite as a function of holding time was observed. In other words, the thermally spiked glass/epoxy composite exhibited the maximum ultimate tensile strength after the specimens were subjected to the greatest holding times at the highest temperature $\left(150^{\circ} \mathrm{C}\right)$.

Moreover, Khalili et al. [21] conducted an experimental study investigating the effect of thermal cycling on the tensile behavior of polymer composites reinforced by basalt and carbon fibers. Woven basalt and carbon fibers, as well as combined basalt and carbon fibers, were used as reinforcement. The specimens were first subjected to a number of thermal cycles (up to 30 cycles) from $-30^{\circ} \mathrm{C}$ to $+220^{\circ} \mathrm{C}$ with a hold time of $3 \mathrm{~min}$ at each temperature and subsequently underwent tensile testing. The degradation in the tensile strength of their basalt reinforced specimens was observed to be less than that observed for their carbon reinforced specimen ( $5 \%$ in comparison to $11 \%$, respectively). Moreover, the effect of thermal cycles on the failure strain was found to be insignificant.

One of the critical considerations concerning the use of adhesives and composites is their long-term performance and durability under harsh environmental loading conditions. Harsh loading states could cause degradation in the stiffness and strength of adhesives and composites. A critical state that adhesive bonded composite joints can be subjected to is thermal fluctuating or cyclic loading, a 
topic that has not been fully explored yet. In other words, a majority of the available relevant research works have considered adhesives and composites that were subjected to monotonic loads, while in many practical applications, mechanical and thermal cyclic loadings are often the prevalent loading states. Therefore, an investigation is carried out to establish the influence of thermal cycles on the mechanical properties of adhesively bonded joints formed by a widely-used epoxy resin, and unidirectional E-glass fiber-reinforced composite made using the resin.

The main objective of the present work is to investigate the influence of thermal cycles on the performance of a commonly used neat epoxy resin, and the E-glass fiber reinforced laminate composite produced with the same resin. This investigation was motivated by our long-term objective of better understanding the influence of thermal cycling on adhesively bonded joints consisted of fiber-reinforced polymer composites adherends. Specifically of the interest is the type of bonded joints used in FRP boatbuilding industry, which are usually formed by the use of commonly-used room-cured epoxy resins. The study will examine the influence of thermal cycling on the degradation of the mechanical properties (i.e. the modulus of elasticity, ultimate axial tensile stress and strain) of the resin and its composite. The Fourier transform-Raman spectrometer analysis is used to investigate the changes in the chemistry of the resin, which could potentially develop as a result of applied thermal cycling. Also, the effect of thermal cycling on the glass transition temperature $\left(\mathrm{T}_{\mathrm{g}}\right)$ of the resin is investigated with Differential Scanning Calorimetry.

\section{Experimental Procedure}

\subsection{Material and Specimens Preparation}

The widely used room-temperature cured West System 105 epoxy resin and 206 hardener (Bay City, MI) were used in this investigation. It should be noted that this resin can be cured under a wide temperature range; for instance, at room temperature, it would fully cure in 24 hours. The resin has a minimum glass transition temperature, $\mathrm{T}_{\mathrm{g}}$, of $60^{\circ} \mathrm{C}$. Typical dog-bone shape coupons with dimensions of $95 \times 10 \times 5 \mathrm{~mm}$ were prepared by pouring the resin into a mold, followed by degassing the resin. Moreover, eight-ply laminated plates were also fabricated using the same resin and a unidirectional E-glass cloth by vacuum-assisted hand lay-up technique. The plates were cut into $250 \times 25 \mathrm{~mm}$ rectangular specimens, with an average thickness of $3.5 \mathrm{~mm}$. The configurations of these two groups of specimens, as illustrated in Figure 1, conform to ASTM D638 [22].

\subsection{Test Procedure}

All tensile tests conducted on the neat epoxy and unidirectional E-glass-epoxy composite specimens were performed as per ASTM D638, using an Instron servo-hydraulic universal test machine (model $8500+$ ), equipped with a $100 \mathrm{kN}$ 


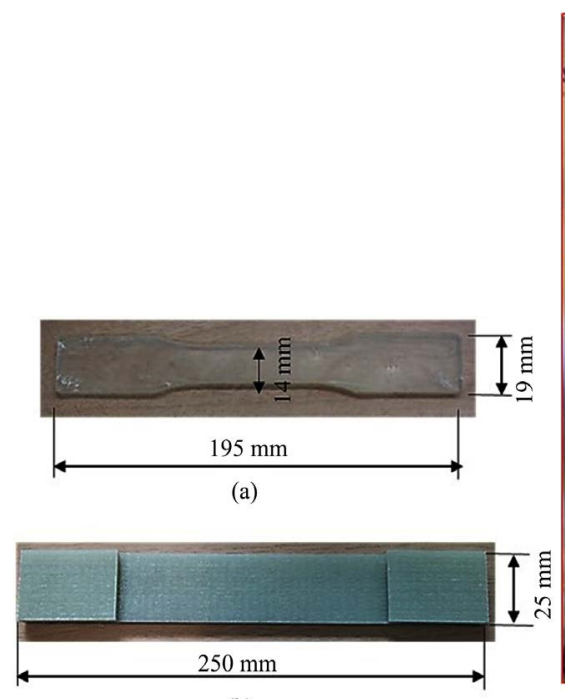

(b)

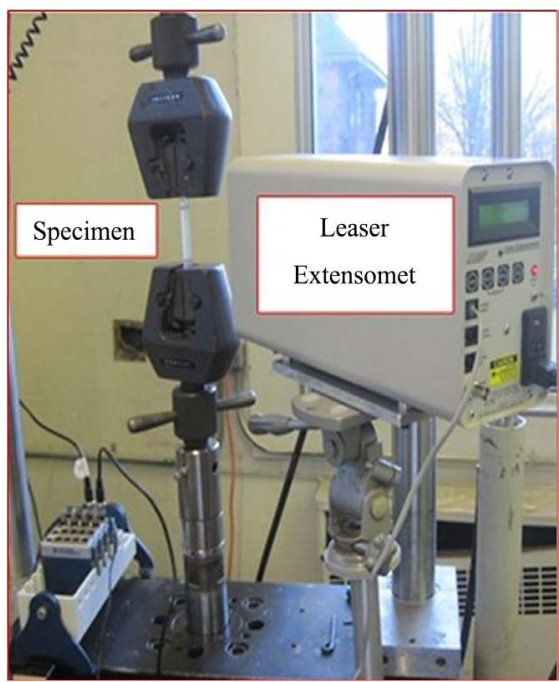

(c)

Figure 1. (a) Dog-bone tensile neat-resin specimen (b) unidirectional E-glass-epoxy specimen and (c) Tensile Test setup.

load cell. A laser extensometer (model LE-05, Electronic Instrument Research, Irwin, PA) was used to record the axial strain in specimens (see Figure 1). Data from the load cell, actuator's displacement, and laser extensometer were acquired through a data-acquisition system (DAQ) and stored in a personal computer. The tests were conducted under displacement-controlled, at a loading rate of $1.5 \mathrm{~mm} / \mathrm{min}$, with a data sampling rate of $50 \mathrm{~Hz}$. The modulus of elasticity was calculated in a semi-automated fashion by using a special code written in Python language, in conjunction with the MATLAB fitting toolbox, which was used for fitting a line to the linear portion of the stress-strain curve.

\subsection{Thermal Cycling Test}

As discussed earlier, several researchers have identified cyclic thermal loading as one of the most critical loading schemes that could affect the life-cycle of ABJs. In several engineering applications, $A B J s$ often experience fluctuating temperatures (cold-warm and vice-versa). Many investigators have considered the cycle range of $-35^{\circ} \mathrm{C}$ to $+45^{\circ} \mathrm{C}$ in their studies [23] [24]. The temperature of $-35^{\circ} \mathrm{C}$ represents the average lowest temperature experienced in most northern hemisphere climates, while $+45^{\circ} \mathrm{C}$ accounts for an average extreme value of service conditions in summer. Note that the higher temperature is well below the glass transition temperature $\left(\mathrm{T}_{\mathrm{g}}\right)$ of the resin considered in this study, which has been rated at a minimum of $60^{\circ} \mathrm{C}$, according to the manufacturer. Cyclic thermal tests were conducted within a bench-top humidity/environmental chamber (the Associated Environmental Systems Model ZBHD-205). The chamber is designed to generate and control low and high-temperature environments in the range of $-65^{\circ} \mathrm{C}$ to $+200^{\circ} \mathrm{C}$ (see Figure 2). The temperature within the chamber was monitored and recorded continually using a thermocouple K-type, controlled by a data-acquisition system (DAQ), hosted by a PC. 
Each heating-cooling cycle included four stages, with each stage of heating and cooling lasting 30 minutes. Figure 2 illustrates the schematic of the thermal cycles, including details of one complete cycle, where the maximum and minimum temperatures within the thermal cycle are denoted by $T_{1}$ and $T_{2}$, respectively.

In total, eight groups of specimens were tested, each subjected to a different total number of cycles as reported in Table 1. After thermal cycling, each specimen underwent tensile testing. Note that group-1 included the "virgin" or baseline specimens that were not subjected to thermal cycling and were just monotonically loaded.

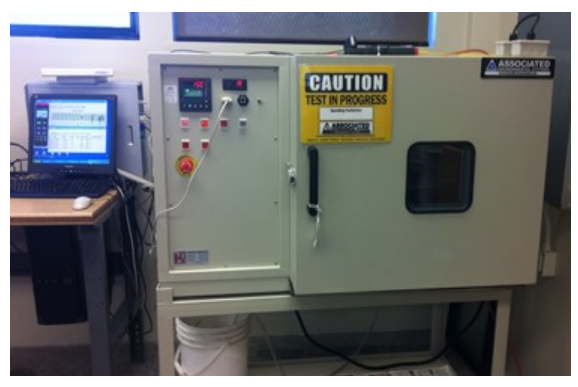

(a)

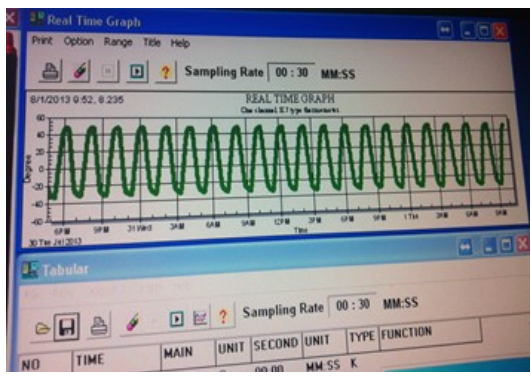

(b)

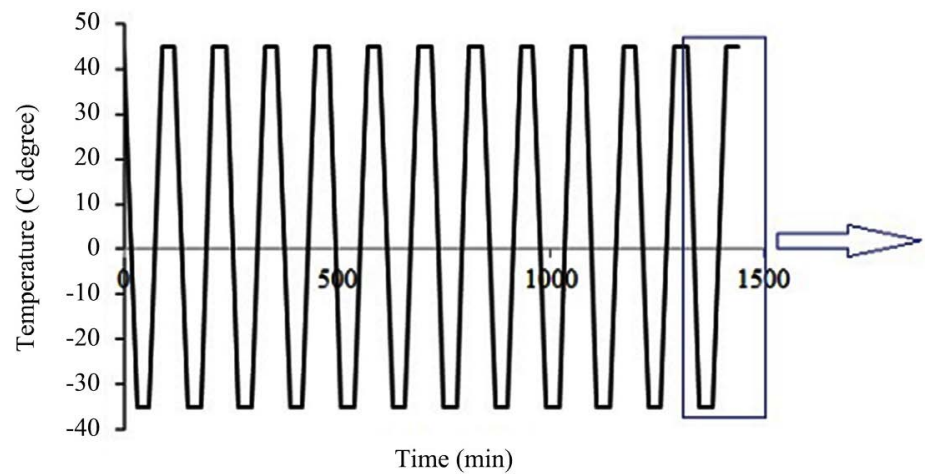

(c)

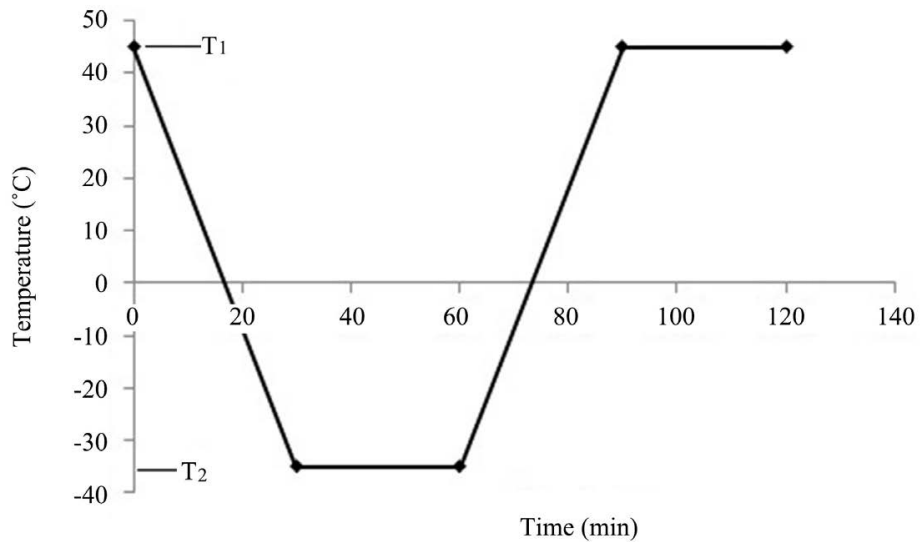

(d)

Figure 2. Test Setup (a) the environmental chamber equipped with a PC; (b) graphic illustration of the applied cycles captured by THERMOLINK program (c) schematics of the applied thermal cycles and (d) one complete cycle. 
Table 1. Identification of specimen groups.

\begin{tabular}{ccccccccc}
\hline Group ID & 1 & 2 & 3 & 4 & 5 & 6 & 7 & 8 \\
\hline $\begin{array}{c}\text { Number of } \\
\text { applied thermal cycles }\end{array}$ & $\begin{array}{c}\text { Zero } \\
\text { (baseline specimens) }\end{array}$ & 150 & 300 & 450 & 600 & 750 & 900 & 1000 \\
\hline
\end{tabular}

\subsection{Fourier Transform-Raman Spectrometer Analysis (FT-Raman)}

Fourier transform-Raman spectroscopy was used to investigate the curing level in each group of specimens after cycling them and identify any chemical changes that could have occurred within the epoxy resin and E-glass FRP as a result of the thermal cycling. Using the FT-Raman, one can identify the types of chemical bonds by producing an infrared absorption spectrum of the material, much similar to molecular "fingerprinting". A Nicolet NXR 9650 FT-Raman spectrometer equipped with a $1064 \mathrm{~nm} \mathrm{Nd:YVO4} \mathrm{Laser} \mathrm{and} \mathrm{InGaAs} \mathrm{detector} \mathrm{were} \mathrm{used.} \mathrm{All}$ spectra were collected with a $2 \mathrm{~cm}^{-1}$ resolution, and the laser power set to 0.5 -Watt power. All FT-Raman spectroscopy evaluations were conducted at room temperature. However, as will be explained later, additional measurements were performed under various isothermal conditions to detect whether additional curing of the polymer took place as a result of the applied thermal cycles.

\subsection{Differential Scanning Calorimetry (DSC)}

Differential Scanning Calorimetry (DSC) analysis was also conducted as per ASTM E1356-08 [25], using a TA Instrument Q200 DSC to evaluate the potential change in the glass transition temperature $\left(\mathrm{T}_{\mathrm{g}}\right)$ of the resin that was cycled at the various thermal cycles noted in Table 1. The DSC analyses were conducted on small samples (approximately $10 \mathrm{mg}$ ) cut from the tested epoxy resin specimens, subsequent to the thermal cycling. They were heated to $150^{\circ} \mathrm{C}$ and then cooled down to $-45^{\circ} \mathrm{C}$, and again heated to $150^{\circ} \mathrm{C}$ using a temperature ramp of $10^{\circ} \mathrm{C} \mathrm{m^{-1 }}$. Replicate samples were runs to ensure consistent $\mathrm{T}_{\mathrm{g}}$ measurements.

\section{Experimental Results}

\subsection{Effect of Thermal Cycles on the Mechanical Properties}

The experimental data were processed to obtain the stress-strain curves of the neat epoxy adhesive and unidirectional E-glass-epoxy composite specimens. Figure 3 illustrates typical stress-strain curves of the neat epoxy and unidirectional E-glass-epoxy specimens.

The influence of thermal cycling is examined through its effect on the modulus of elasticity, ultimate tensile strength and strain of the materials. Figure 4 and Figure 5 illustrate the summary of the degradation levels in the modulus of elasticity, ultimate tensile strength and strain corresponding to the ultimate strength, respectively, as a function of the total number of thermal cycles the neat resin and FRP were subjected to. Note that each bar-chart represents the average result of at least four tested specimens. 


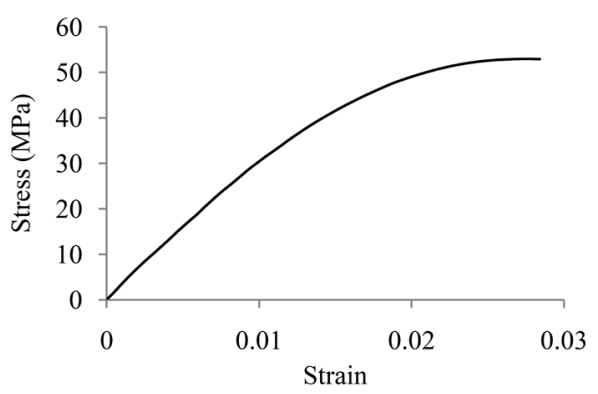

(a)

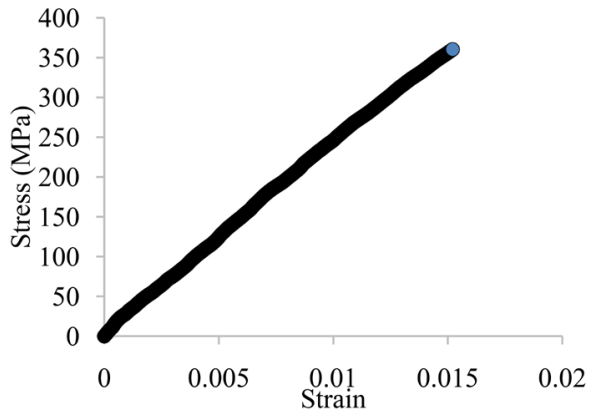

(b)

Figure 3. Typical stress-strain curve for (a) the neat epoxy and (b) FRP.

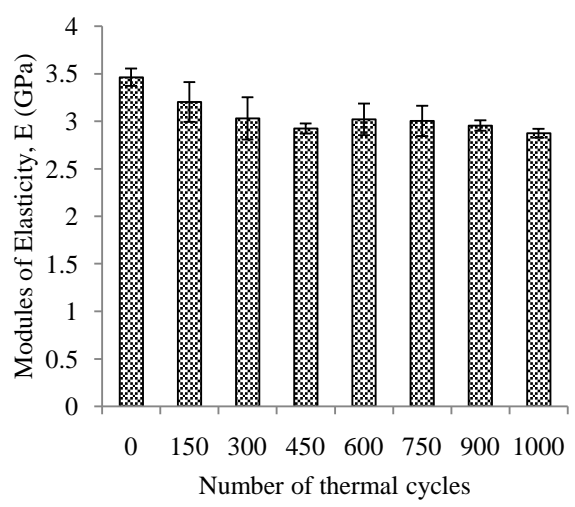

(a)

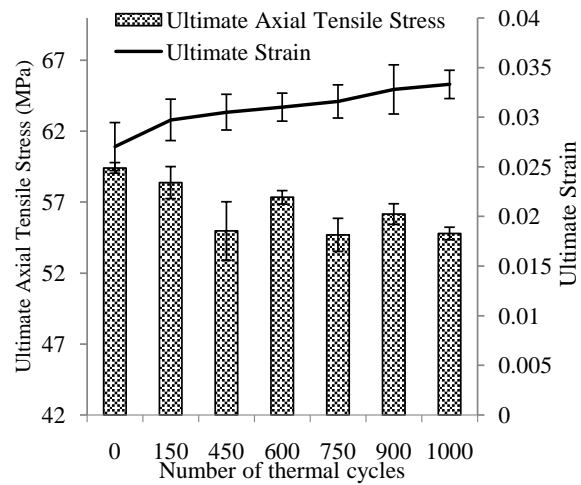

(b)

Figure 4. Degradation of the mechanical properties of the neat epoxy as a function of applied thermal cycles, (a) modules of elasticity, (b) ultimate axial tensile stress and strain. 


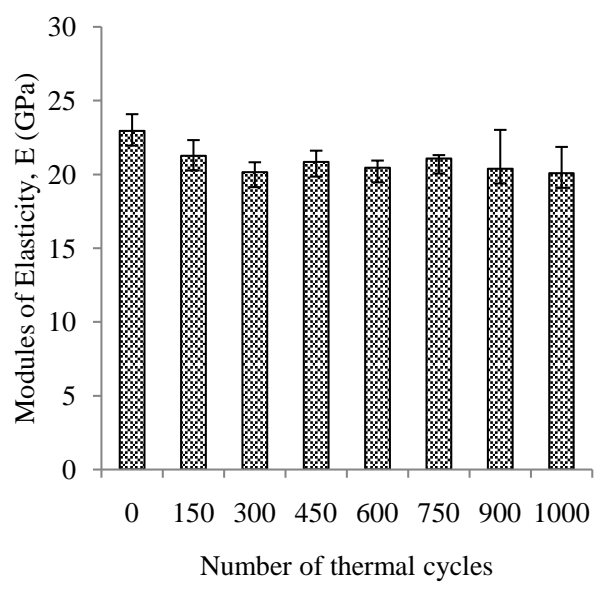

(a)

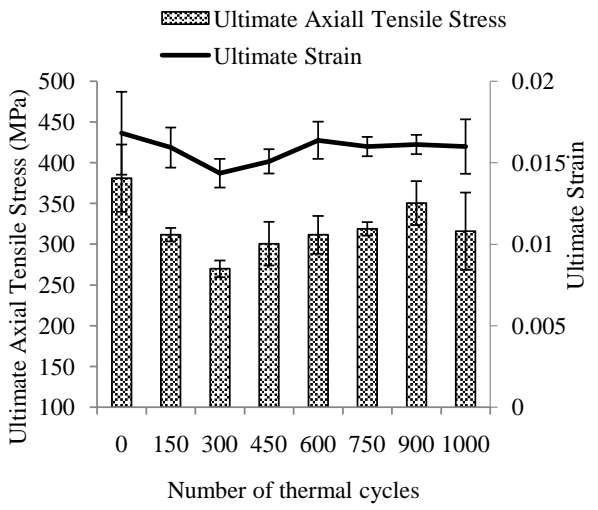

(b)

Figure 5. Degradation of the mechanical properties of glass FRP as a function of the applied thermal cycle, (a) modules of elasticity, (b) ultimate axial tensile stress and strain.

Notable degradations in the modulus of elasticity, and ultimate tensile stress and significant softening of the resin response are observed in both the resin and FRP. However, as expected, the decrease in the properties of the resin is more significant than that in FRP. This is because unidirectional FRP's strength and stiffness are fiber dominant properties, as opposed to being matrix dominant. Note that the modulus of elasticity and the ultimate strength of the resin were decreased by approximately $17 \%$ and $8 \%$ after being exposed to the maximum number of applied thermal cycles (i.e. 1000). However, surprisingly, similar levels of degradation (i.e. $16 \%$ and $8 \%$, respectively), took place in the specimens at much earlier stages of thermal cycling (at, i.e. 300 - 400 cycles). The apparent levelling off of the degradation observable after 300 cycles may be attributed to the fact that the resin may not have been fully cured, and that its ultimate curing occurring after a few thermal cycles curbed the rate of degradation of its mechanical properties. In other words, it appears that the polymer chains were strengthened after having been exposed to a certain number of cycles, thus becoming more resilient against the subsequent applied thermal cycles. This postulation will be discussed further in the following section.

Moreover, degradations in the modulus of elasticity and ultimate tensile 
strength of the E-glass FRP after 1000 cycles were approximately $12 \%$ and $13 \%$, respectively. Similar to the resin's response, the FRP also experienced greater levels of degradation after 300 thermal cycles (by approximately 12\% and 29\% in the modulus of elasticity and ultimate tensile strength, respectively) in comparison to those observed after 1000 thermal cycles. Furthermore, an apparent strain hardening of approximately $20 \%$ was observed as the number of thermal cycles increased, up to 300 cycles. However, after that stage, the strain capacity of the FRP softened markedly (as much as $25 \%$ ). The failure modes of the unidirectional specimens were consistent, regardless of the number of thermal cycles the specimen had been exposed to.

\subsection{Fourier Transform-Raman Spectroscopy}

The phenomenon observed above (i.e. the apparent improvement in the properties after the application of a certain number of thermal cycles), is consistent with the findings of an investigation that was conducted on the same resin within our research group a few years ago [26]. It also corroborates with the findings reported by other investigators [16] [27] [28] [29]. To gain a better understanding of the effect of thermal cycles on the resin and its FRP, and to further explore whether any change in resin's chemistry was responsible for the observed phenomenon, further exploration was carried out using a Raman spectrometer. The Raman spectroscopy measures the rotational and vibrational transitions in molecules. These features can be used to detect and identify specific changes in chemical bonds of polymers, which could develop from exposure to thermal cycling. The relative intensity of Raman spectra peaks is also directly proportional to the relative and proportional concentration of active molecules of the components of polymers [30] [31] [32] [33].

Figures 6-8 illustrate the typical variations in signals obtained from the FT-Raman spectroscopy of the epoxy resin and its FRP, respectively, after having been exposed to various numbers of thermal cycles. The spectra look similar for all specimens in the range of 500 to $4000 \mathrm{~cm}^{-1}$, and they follow a similar trend. This would indicate that the chemical structure of the resin did not undergo any major changes after having been exposed to the cycles of heating and cooling. Moreover, all spectra peaks are consistent with those reported in the literature.

However, several peaks are observed in the spectra, which would indicate strong connections of resin's chemical components ( $\mathrm{R}^{-} \mathrm{C}_{\mathrm{C}_{\mathrm{R}}}$ [ [34]. The changes observed in $\mathrm{C}=\mathrm{C}$ stretching of the benzene ring at $1600 \mathrm{~cm}^{-1}$ (asym stretch), and the Raman line at $2860 \mathrm{~cm}^{-1}$ are very intense, corresponding to $\mathrm{CH}_{3}$ sym. stretch. Also, the observed Raman shift absorption to increase degassing at $\sim 3000$ and $\sim 3100 \mathrm{~cm}^{-1}$ (see Figure 6), is believed to be due to stretching vibration of the secondary amino group associated with the hardener when reacted with the resin. Accordingly, these peaks can be used as a reference for assessing the degree of cure of adhesive, which is indicated by the change in intensity of the peaks, attributed to the epoxide group. 


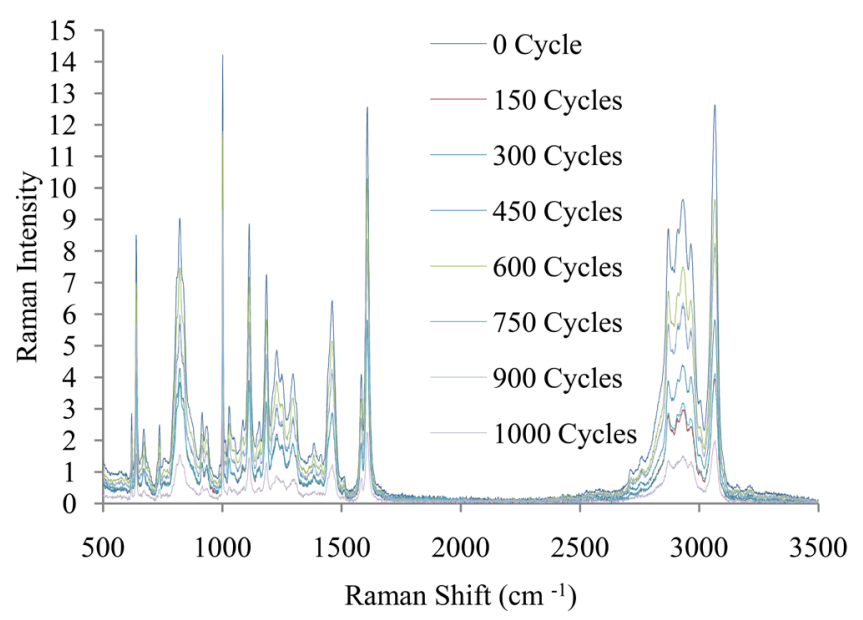

Figure 6. FT-Raman spectra of the epoxy resin specimens after having been subjected to various thermal cycles.

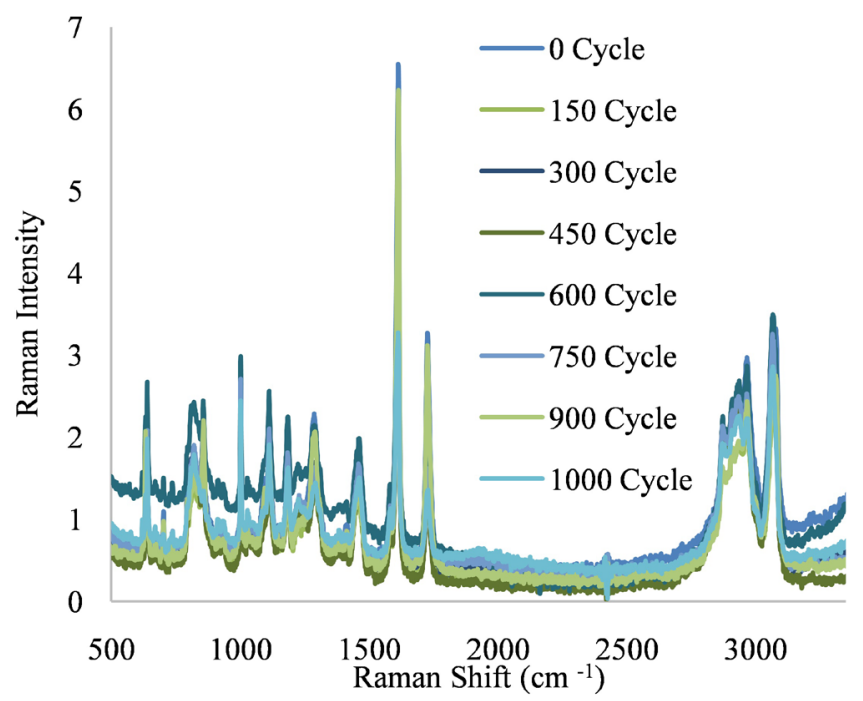

Figure 7. FT-Raman spectrometer of the FRP specimens after having been subjected to various thermal cycles.

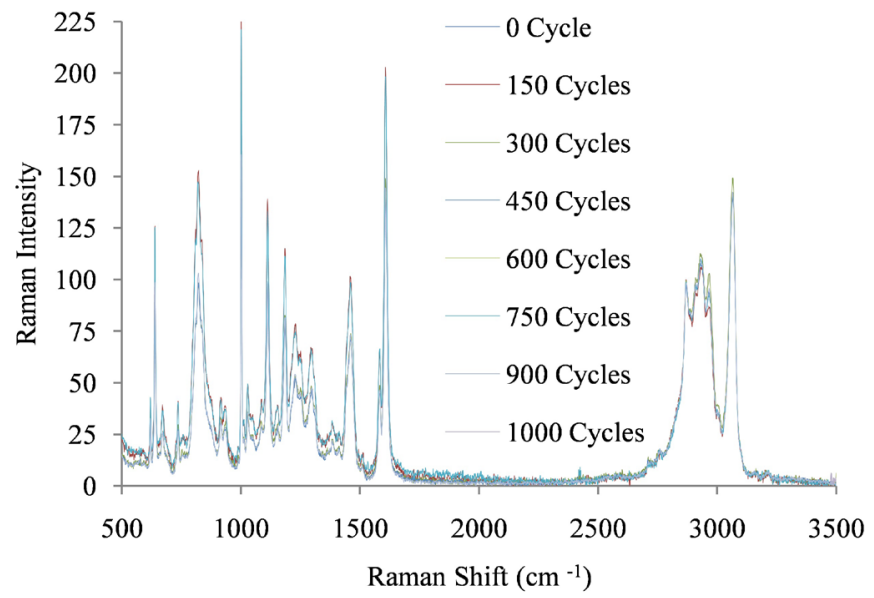

Figure 8. Raman spectra normalized with respect to line at $2860 \mathrm{~cm}^{-1}$ for the epoxy resin. 
Moreover, to explore any evidence of chemical degradation, the relative spectral intensities were also examined. For that, all spectra were scaled with respect to the maximum value (i.e. at $2860 \mathrm{~cm}^{-1}$ ), as illustrated in Figure 8. As mentioned, the $2860 \mathrm{~cm}^{-1}$ shift was selected because it is very intense, so that the measurements can be done with high accuracy at that intensity. Moreover, it is not associated with the polymer backbone; therefore, it should not be changing the absolute intensity, even if chemical changes take place in the polymer.

Farquharson et al. [35] showed that Raman shifts at $\sim 1600 \mathrm{~cm}^{-1}$ are due to a polymer's backbone and that their intensity could be diminished as the polymer degrades. In our case, the line at $\sim 1610 \mathrm{~cm}^{-1}$ does not follow a monatomic decrease as a function of thermal cycles. The signs of curing in such resins are identifiable by the existence of the Raman lines at $\sim 1640 \mathrm{~cm}^{-1}$, reflecting insufficient curing, and the lines at $\sim 1610 \mathrm{~cm}^{-1}$, indicating an increase in curing. Therefore, the variation in the peak ratios would be an indication of further curing of the resin. Examination of the spectra evidenced no sign of the $\sim 1640$ $\mathrm{cm}^{-1}$ peak as a function of increasing thermal cycles. Therefore, this would indicate that the original samples were already fully cured.

Despite the above-noted results, the nonlinear variation of the mechanical properties remains quite perplexing. To further explore the cause of such a variation, additional Raman spectroscopies were conducted. In this part of the examination, selected groups of the FRP specimens (i.e. those that were subjected to 0,600 and 1000 thermal cycles (groups 1, 5 and 8)), were further examined. The spectra of these specimens were obtained under the isothermal regimes of $20^{\circ} \mathrm{C}$, then heated up to $140^{\circ} \mathrm{C}$, and subsequently cooled to $55^{\circ} \mathrm{C}$, and then let cool down to room temperature $\left(20^{\circ} \mathrm{C}\right)$.

The spectra for this part of the examination are illustrated in Figure 9. Evidence of very strong bonds is noted at the next shift peaks (i.e. at $\sim 1610,1720$, 2970 and $3070 \mathrm{~cm}^{-1}$ ).

As can be seen, one cannot decipher any significant conclusion from the plots. It should be noted that deciphering the data becomes even more challenging because the curves at each isothermal regime associated with specimens subjected to the various thermal cycles virtually fall on top of one another. Nevertheless, $\mathrm{C}=\mathrm{C}$ multiple bands stretching of phenyl ring are evidence at a strong bond at $\sim 1610 \mathrm{~cm}^{-1}$. As stated earlier, however, the shifts at $\sim 1600 \mathrm{~cm}^{-1}$ are due to the backbone of the polymer, and it can diminish in intensity as the polymer degrades. The large emission observed at $140^{\circ} \mathrm{C}$ above $\sim 3000 \mathrm{~cm}^{-1}$ is an artifact heating emission from the variable temperature cell; this peak is confirmed with no sample present at the same temperature.

To further enhance the variation of the Raman spectra, an attempt has been made to show the peaks in a bar-chart format, as illustrated in Figure 10(a). Further clarification can be seen by our attempt in presenting the variation of the Raman intensity as a function of the applied thermal cycles, shown in Figure 10(b). There seems to be clear evidence that a reaction (postulated to be due to further curing of the resin) occurred due to the application of thermal cycles (up 
to 600 cycles). This evidence is clear when considering the variation of the intensity at $1610 \mathrm{~cm}^{-1}$ shift, as well as the other selected shifts. This follows the trend observed in the curves illustrating the variation in mechanical properties, as illustrated in Figure 4 and Figure 5.

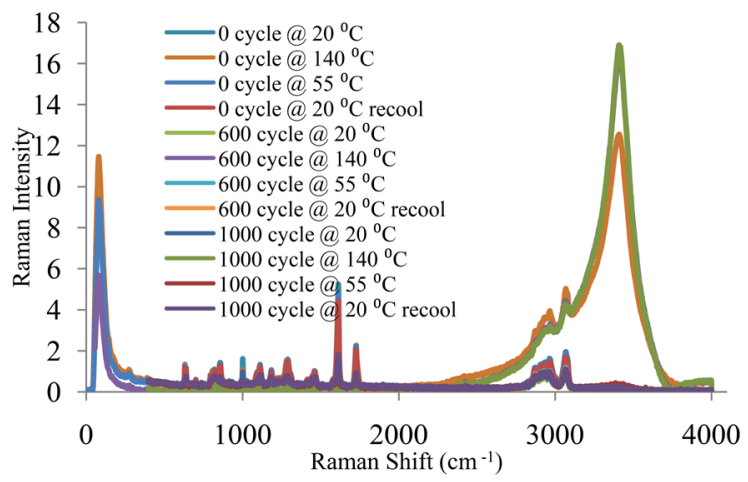

Figure 9. FT-Raman spectrometer of the FRP specimens tested at different thermal cycling number.

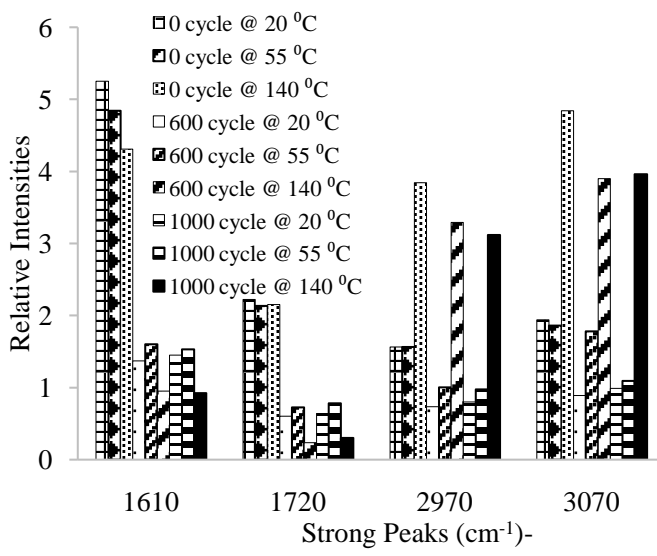

(a)

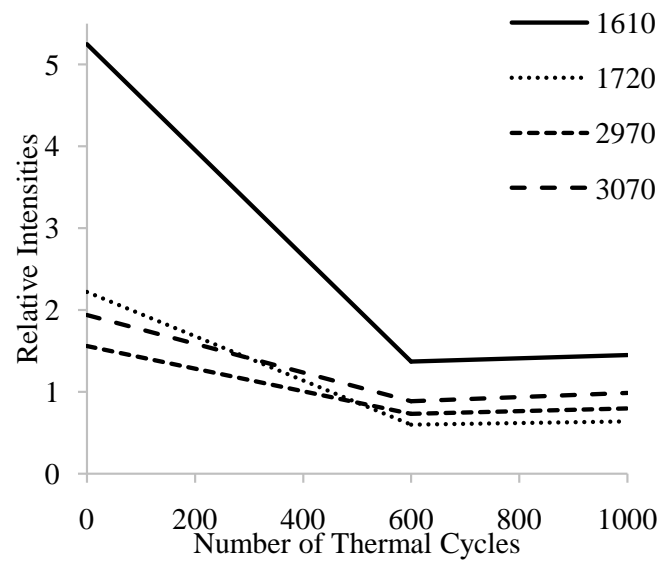

(b)

Figure 10. Influence of thermal cycles on the Raman intensity in FRP specimens (a) under various isothermal regimes, and (b) variation of the intensity at a specific isothermal regime. 


\subsection{Influence of the Thermal Cycles on Glass Transition Temperature $\left(\mathrm{T}_{\mathrm{g}}\right)$}

The DSC data was processed using Universal Analysis 2000 software (TA Instruments). Results obtained from DSC thermograms revealed the effect of thermal cycles on the glass transition temperature $\left(\mathrm{T}_{\mathrm{g}}\right)$ of the resin. The $\mathrm{T}_{\mathrm{g}}$ temperatures are evaluated by the inflection point through the glass transition obtained during sample heating. Figure 11(a) illustrates the resulting thermograms of the specimen at different thermal cycling numbers (i.e. the data obtained from the DSC instrument). Moreover, Figure 11(b) illustrates the change in the glass transition temperature of the epoxy resin after exposure to various thermal cycles.

As seen in Figure 11(a), thermograms of the epoxy resin after undergoing thermal cycling show a steady heat flow, regardless of the number of cycles applied to the specimens. Figure 11(b) illustrates the variation in the glass transition temperature of the resin as a function of thermal cycles. A decreasing trend in $T_{g}$ is observed as the samples undergo thermal cycling. However, interestingly, in concert with the variation seen in the modulus of elasticity and ultimate strength of the resin, as shown in Figure 3, one can see a sudden change in $\mathrm{T}_{\mathrm{g}}$ value after resin's exposure to 300 thermal cycles. In all, resin's $T_{g}$ degrades by $9 \%$ after having been subjected to a 1000 thermal cycle.

\section{Summary and Conclusion}

An investigation was carried out to establish the influence of thermal cycles on the mechanical properties of a widely-used epoxy resin, and the unidirectional E-glass fiber-reinforced composite made using the resin. Specifically, the degradation of the resin as a function of applied thermal cycles was the main goal of the investigation. The outcomes of the investigation are summarized as follows:

- Thermal cycles caused a notable degradation in the stiffness and strength of the epoxy resin. The modulus of elasticity and ultimate tensile strength of the resin after exposure to 1000 thermal cycles were degraded by approximately $17 \%$ and $8 \%$, respectively.

- While resins properties are not supposed to govern the axial strength and stiffness of unidirectional fiber-reinforced composites, that was not the case in this investigation. In fact, mechanical test results revealed degradations levels of $12 \%$ and $13 \%$, respectively, in the modulus of elasticity and ultimate tensile strength of the specimens. Interestingly, initially, the FRP exhibited stiffer response as thermal cycles were increased (up to 300 cycles); however, upon increasing thermal cycles, FRP's response softened significantly (by as much as $25 \%$ ).

- The FT-Raman spectra obtained for the neat resin exposed to various numbers of thermal cycles showed a similar characteristic. In other words, a variation in the intensity of the Raman spectra at lower thermal cycles was observed; however, the intensity in resin specimens that were exposed to 600 and greater numbers of thermal cycles levelled off. 


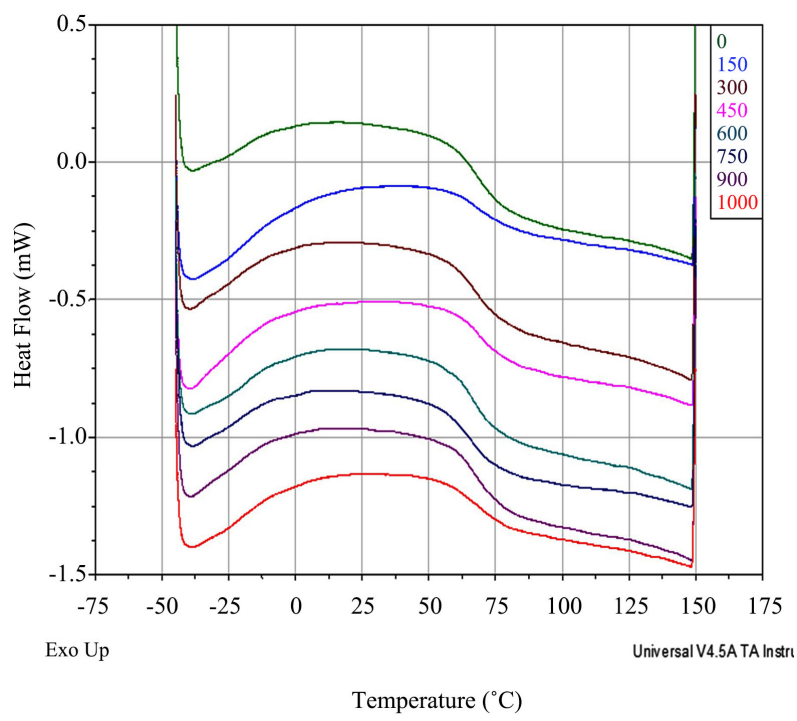

(a)

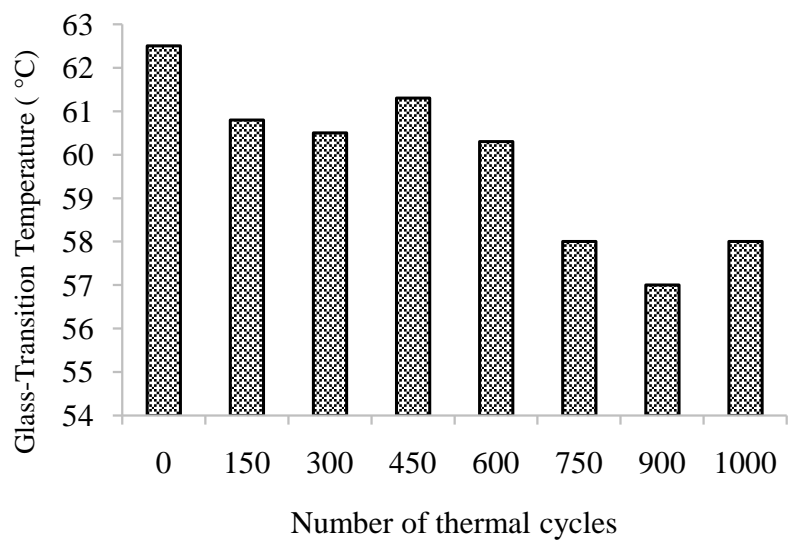

(b)

Figure 11. Variation in (a) thermograms of the epoxy resin after undergoing thermal cycling and (b) glass transition temperature as a function of thermal cycling.

- A maximum change in the glass transition temperature $\left(\mathrm{T}_{\mathrm{g}}\right)$ of $9 \%$ was observed in the resin as a result of the applied thermal cycling. The change in $\mathrm{T}_{\mathrm{g}}$ as a function of applied thermal cycles was in concert with the observed variation in the stiffness and strength of the resin.

\section{Acknowledgements}

The financial support from the Higher-Education Ministry of Libya, and the National Science and Engineering Research Council of Canada (NSERC,) are gratefully acknowledged. Also, the authors recognize the assistance of M. Johnson in carrying out the Raman experiments, CFI and other partners that fund the Clean Technologies Research Institute. Our special thank also goes to Professor M. A. White for her helpful assistance in interpreting the results and related discussions. Also, the authors acknowledge the assistance of Dr. G. Mazzanti and O. AL Qatami in operating the DSC instrument. 


\section{Conflicts of Interest}

The authors declare no conflicts of interest regarding the publication of this paper.

\section{References}

[1] Adams, R.D. (2005) Adhesive Bonding: Science, Technology and Applications. Elsevier, Boca Roton.

[2] Viana, G., Costa, M., Banea, M.D. and da Silva, L.F.M. (2017) Behaviour of Environmentally Degraded Epoxy Adhesives as a Function of Temperature. The Journal of Adhesion, 93, 95-112. https://doi.org/10.1080/00218464.2016.1179118

[3] Hancox, N.L. (1998) Thermal Effects on Polymer Matrix Composites: Part 1. Thermal Cycling. Materials and Design, 19, 85-91. https://doi.org/10.1016/S0261-3069(98)00018-1

[4] Robert, M. and Benmokrane, B. (2009) Behavior of GFRP Reinforcing Bars Subjected to Extreme Temperatures. Journal of Composites for Construction, 14, 353-360. https://doi.org/10.1061/(ASCE)CC.1943-5614.0000092

[5] Wang, J., Gang, R.H., Liang, R. and Liu, W. (2016) Durability and Prediction Models of Fiber-Reinforced Polymer Composites under Various Environmental Conditions: A Critical Review. Journal of Reinforced Plastics and Composites, 35, 179-211. https://doi.org/10.1177/0731684415610920

[6] Vauthier, E., Abry, J.C., Bailliez, T. and Chateauminois, A. (1998) Interactions between Hygrothermal Ageing and Fatigue Damage in Unidirectional Glass/Epoxy Composites. Composites Science and Technology, 58, 687-692. https://doi.org/10.1016/S0266-3538(97)00149-8

[7] Budhe, S., Banea, M.D., De Barros, S. and Da Silva, L.F.M. (2017) An Updated Review of Adhesively Bonded Joints in Composite Materials. International Journal of Adhesion and Adhesives, 72, 30-42.

https://doi.org/10.1016/j.ijadhadh.2016.10.010

[8] Kutz, M. (2018) Handbook of Environmental Degradation of Materials. William Andrew, New York.

[9] Fiedler, B.O.D.O., Hobbiebrunken, T.H.O.M.A.S., Hojo, M. and Schulte, K.A.R.L. (2005) Influence of Stress State and Temperature on the Strength of Epoxy Resins. 11 th International Conference on Fracture, Turin, 20-25 March 2005, 2271-2275.

[10] Bascom, W.D. and Cottington, R.L. (1976) Effect of Temperature on the Adhesive Fracture Behavior of an Elastomer-Epoxy Resin. The Journal of Adhesion, 7, 333-346. https://doi.org/10.1080/00218467608075063

[11] Grohs, J.W. (2007) Comparing in Situ and Bulk Constitutive Properties of a Structural Adhesive. Master Dissertation, Virginia Polytechnic Institute and State University, Blacksburg, Virginia.

[12] Da Silva, L.F. and Adams, R.D. (2005) Measurement of the Mechanical Properties of Structural Adhesives in Tension and Shear over a Wide Range of Temperatures. Journal of Adhesion Science and Technology, 19, 109-141. https://doi.org/10.1163/1568561053148449

[13] Hawileh, R.A., Abu-Obeidah, A., Abdalla, J.A. and Al-Tamimi, A. (2015) Temperature Effect on the Mechanical Properties of Carbon, Glass and Carbon-Glass FRP Laminates. Construction and Building Materials, 75, 342-348.

https://doi.org/10.3390/polym8050196 
[14] Ou, Y., Zhu, D., Zhang, H., Huang, L., Yao, Y., Li, G. and Mobasher, B. (2016) Mechanical Characterization of the Tensile Properties of Glass Fiber and Its Reinforced Polymer (GFRP) Composite under Varying Strain Rates and Temperatures. Polymers, 8, 196. https://doi.org/10.3390/polym8050196

[15] Eslami, S., Taheri-Behrooz, F. and Taheri, F. (2012) Effects of Aging Temperature on Moisture Absorption of Perforated GFRP. Advances in Materials Science and Engineering, 2012, Article ID: 303014. https://doi.org/10.1155/2012/303014

[16] Kumar, B.G., Singh, R.P. and Nakamura, T. (2002) Degradation of Carbon Fiber-Reinforced Epoxy Composites by Ultraviolet Radiation and Condensation. Journal of Composite Materials, 36, 2713-2733. https://doi.org/10.1177/002199802761675511

[17] Grammatikos, S.A., Evernden, M., Mitchels, J., Zafari, B., Mottram, J.T. and Papanicolaou, G.C. (2016) On the Response to Hygrothermal Aging of Pultruded FRPs Used in the Civil Engineering Sector. Materials \& Design, 96, 283-295. https://doi.org/10.1016/j.matdes.2016.02.026

[18] Grammatikos, S.A., Jones, R.G., Evernden, M. and Correia, J.R. (2016) Thermal Cycling Effects on the Durability of a Pultruded GFRP Material for Off-Shore Civil Engineering Structures. Composite Structures, 153, 297-310. https://doi.org/10.1016/j.compstruct.2016.05.085

[19] Dogan, A. and Atas, C. (2016) Variation of the Mechanical Properties of E-Glass/Epoxy Composites Subjected to Hygrothermal Aging. Journal of composite materials, 50, 637-646. https://doi.org/10.1177/0021998315580451

[20] Mahato, K.K., Dutta, K. and Ray, B.C. (2017) Effect of Thermal Spike Conditioning on the Tensile Behavior of Glass/Epoxy Composites.

[21] Khalili, S.M.R., Najafi, M. and Eslami-Farsani, R. (2017) Effect of Thermal Cycling on the Tensile Behavior of Polymer Composites Reinforced by Basalt and Carbon Fibers. Mechanics of Composite Materials, 52, 807-816. https://doi.org/10.1007/s11029-017-9632-5

[22] ASTM International (2015) ASTM D638-14, Standard Test Method for Tensile Properties of Plastics. ASTM International.

[23] Johnson, W.S. and Butkus, L.M. (1998) Considering Environmental Conditions in the Design of Bonded Structures: A Fracture Mechanics Approach. Fatigue and Fracture of Engineering Materials and Structures, 21, 465-478.

https://doi.org/10.1046/j.1460-2695.1998.00533.x

[24] Broughton, W.R., Mera, R.D. and Hinopoulos, G. (1999) Cyclic Fatigue Testing of Adhesive Joints: Environmental Effects. NPL Report CMMT (A) 192, 1-18.

[25] ASTM, S. (2014) E1356-08. Standard Test Method for Assignment of the Glass Transition Temperatures by Differential Scanning Calorimetry, American Society of Testing and Materials, Philadelphia, USA.

[26] Baftechi, S. (2008) Effect of Thermal Loading on Metal/Fiber-Reinforced Composite Interface. Master Thesis, Dalhousie University, Halifax Canada.

[27] Vašková, H. and Křesálek, V. (2011) Raman Spectroscopy of Epoxy Resin Crosslinking. 13th WSEAS International Conference on Automation Control, Modeling and Simulation, Lanzarote, 27-29 May 2011, 357-361.

[28] Hardis, R., Jessop, J.L., Peters, F.E. and Kessler, M.R. (2013) Cure Kinetics Characterization and Monitoring of an Epoxy Resin Using DSC, Raman Spectroscopy, and DEA. Composites Part A: Applied Science and Manufacturing, 49, 100-108. https://doi.org/10.1016/j.compositesa.2013.01.021 
[29] Cabral-Fonseca, S., Correia, J.R., Rodrigues, M.P. and Branco, F.A. (2012) Artificial Accelerated Ageing of GFRP Pultruded Profiles Made of Polyester and Vinylester Resins: Characterisation of Physical-Chemical and Mechanical Damage. Strain, 48, 162-173. https://doi.org/10.1111/j.1475-1305.2011.00810.x

[30] Ajiboye, G.I. (2012) Industrially Relevant Epoxy-Acrylate Hybrid Resin Photopolymerizations. The University of Iowa, USA. https://doi.org/10.17077/etd.0xa1exp7

[31] Crawford, A., Silva, E., York, K. and Li, C. (2017) Raman Spectroscopy: A Comprehensive Review. Department of Textile Engineering, Chemistry and Science, North Carolina State University.

[32] Barbosa, A.Q., Da Silva, L.F.M. and Öchsner, A. (2015) Hygrothermal Aging of an Adhesive Reinforced with Microparticles of Cork. Journal of Adhesion Science and Technology, 29, 1714-1732. https://doi.org/10.1080/01694243.2015.1041358

[33] Foulc, M.P., Bergeret, A., Ferry, L., Ienny, P. and Crespy, A. (2005) Study of Hygrothermal Ageing of Glass Fibre Reinforced PET Composites. Polymer Degradation and Stability, 89, 461-470.

https://doi.org/10.1016/j.polymdegradstab.2005.01.025

[34] McCreery, R.L. (2005) Raman Spectroscopy for Chemical Analysis. Vol. 225, John Wiley and Sons, New York.

[35] Farquharson, S., Bassilakis, R., DiTaranto, M.B., Haigis, J.R., Smith, W.W., Solomon, P.R. and Wallace, J.F. (1994) Measurement of Thermal Degradation in Epoxy Composites by Fourier Transform Raman Spectroscopy. Fiber Optic Physical Sensors in Manufacturing and Transportation, 2072, 319-332. https://doi.org/10.1117/12.166867 